\title{
ON THE OPTIMALITY OF PAYG PENSION SYSTEMS IN AN ENDOGENOUS FERTILITY SETTING
}

\author{
G. ABÍO \\ G. MAHIEU \\ C. PATXOT \\ CESIFO WORKING PAPER NO. 1050 \\ CATEGORY 1: PubliC FinANCE \\ OCTOBER 2003
}

Presented at Venice Summer Institute, Workshop on “Taxation and the Family”, July 2003

An electronic version of the paper may be downloaded

- from the SSRN website: www.SSRN.com

- from the CESifo website: www.CESifo.de 


\title{
ON THE OPTIMALITY OF PAYG PENSION SYSTEMS IN AN ENDOGENOUS FERTILITY SETTING
}

\begin{abstract}
In order to help in designing an accurate pension reform, we determine the resource allocation in an endogenous fertility model that generates an endogenous demographic transition by means of distinguishing between female and male labor. We analyze the problem of the optimal solution and characterize the decentralization of the first best. We show that a pension policy linking pension benefits to the number of children acts as a corrective tax system able to restore both the optimal capital stock and the optimal rate of population growth as a single instrument. We also show that neither a Beveridgean pension scheme nor a Bismarckian one can decentralize the first best.
\end{abstract}

JEL Code: H55 J13, J18, E62.

Keywords: demographic transition, endogenous fertility, pay-as-you-go pension system, golden rule.

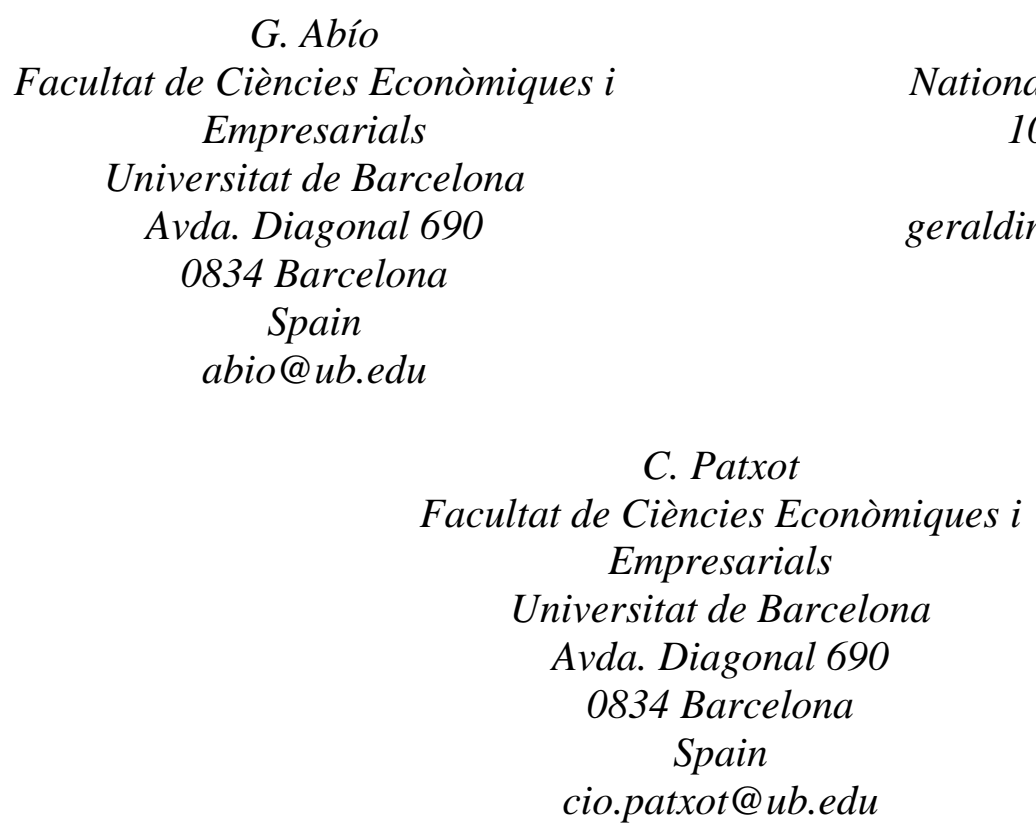

The authors acknowledge financial help from the Project SEC2002-00019. We also thank the participants of the $17^{\text {th }}$ annual congress of the European Economic Association (EEA) held in Venice in August 2002 for helpful comments. 


\section{Introduction}

In recent decades declining fertility together with increasing longevity has resulted in population ageing in most OECD countries. This, by an increase in the dependency ratio, has placed financial pressure on pay-asyou-go (PAYG) pension systems.

Indeed, the present demographic crisis that the social security system is facing is a direct result of the way in which the system is defined. A PAYG system in its purest state is one in which the pensions that are distributed to the retired population each period are derived from the contributions received from the active population in the same period. In this way the system is financially balanced every year. However, in most countries the system promises a pension which is solely dependent on the evolution in wages and not on demographic evolution ${ }^{1}$. This may never come to constitute a problem as long as the population structure remains stable. Yet when the dependency ratio drops, the system does not collect enough money to pay out all the promised pensions, and so it slides into a crisis. In fact, any increase in the dependency ratio needs to be matched by a cut in pension benefits ${ }^{2}$ and/or an increase in payroll taxes. If neither of these reforms is implemented, the system starts accumulation debt, and eventually a solution must be fouund in order to finance the system. This

1 In most countries there is a combination of the so-called Beveridgean and Bismarckian systems. In the first, the same fixed level of pension benefits is given to all beneficiaries with redistributive purposes, while in the second the pension formula established a replacement on an average of the last wages adjusted for inflation.

${ }^{2}$ Either by reducing the pension level or by postponing the retirement age. 
accumulation of debt will unavoidably appear in a number of OECD countries in the following decades unless drastic reforms are undertaken. The current debate on social security reform mostly refers to the possibility of switching to a less demographic dependant system.

Obviously, to avoid the PAYG system's dependency on demographic stability and to make it financially feasible, pensions should be defined in such a way that they satisfy the budgetary constraints of the system; that is, they should be proportional to future wages and to the population growth rate, as this link operates in macroeconomic terms. Hence, an intuitive reform of the pension system would be to link, at least partially, pension benefits to the number of children in the pension benefit formula. On the other hand, it is worth analyzing the effect of such a policy on the economy, and in particular its influence on fertility, which is often ignored.

The role of intergenerational transfers in overlapping-generations (OLG) models was first analyzed within an exogenous fertility framework. In such a framework, it has been well established that the competitive equilibrium is generally different from the social optimum ${ }^{3}$. A variety of instruments can be introduced in the competitive economy in order to achieve the optimal capitallabor ratio, defined by the golden rule. Samuelson (1975) derived the optimal growth rate for population in the simple two-period Diamond (1965) OLG model (in which agents do not choose fertility), and showed that even if the economy is on the golden rule, it might not be in the social optimum as long as the population growth rate differs from its optimal value. Hence, there is not only one but two potential inefficiencies that must be corrected in the competitive equilibrium. One is the achievement of the optimal population growth rate and the other is the achievement of the golden rule. In fact, Samuelson (1975) shows that if the population growth rate stands -by chance- at its optimal value, the centralized and decentralized equilibria coincide ${ }^{4}$. The fact that the competitive equilibrium is different from the social optimum in OLG models with exogenous population growth is after all perfectly reasonable. What would have been surprising is that for a given -non-chosen, thus most probably non-optimalpopulation growth rate, the social optimum was reached. Obviously, an endogenous fertility setting is needed to analyze policy instruments that lead the competitive economy to the first best through their influence on fertility.

In order to be consistent with the observed fertility evolution, we endogenize fertility using a model that is able to explain and reproduce the demographic transition at the origin of the financial problems of most PAYG pension systems. Apart from the social security hypothesis ${ }^{5}$, the various models that generate an endogenous demographic transition are usually based on one of the following two

\footnotetext{
${ }^{3}$ See de la Croix and Michel (2002) for a recent textbook on OLG models with exogenous fertility.

${ }^{4}$ This is his Serendipity Theorem.

${ }^{5}$ See for example Cigno (1993) and Wigger (1999). According to this hypothesis, if individuals have children for an investment motive, the introduction of a PAYG pension system would have been responsible for the decline in fertility observed in many OECD countries in the last decades.
} 
arguments. One deals with the substitution of quality for quantity of children due to economic development. Becker, Murphy and Tamura (1990) and Galor and Weil (2000) rely on this argument in different endogenous growth settings. The other main argument put forward is the increase in the opportunity cost of having children experienced by women in a developed economy. This argument is attractive because, apart from explaining the demographic transition, it is also able to replicate the observed parallel increase in female labor participation. This paper focuses on this last explanation, following Galor and Weil (1996).

Some theoretical models with endogenous fertility have studied the capacity of an optimal intergenerational transfer to solve the pension crisis, but most of these models are not able to replicate the drop in fertility observed since the sixties. For example, Eckstein and Wolpin (1985) introduce a voluntary social security program that gives a return equal to the population growth rate, although this system does not ensure a financial equilibrium out of the steady state. Bental (1989) introduces a PAYG system similar to the one we propose in an economy where children support their parents according to an exogenous social norm. Peters (1995) investigates optimality in a model with endogenous growth. Schweizer (1996) establishes an isomorphism between the problem of optimal population growth in OLG models and the problem of determining optimal club size in local public goods models. Finally, Kolmar (1997, 2001) focuses on the effects of similar pension policies in an open economy.

The paper is organized as follows. In Section 2 we describe the model with endogenous fertility. Section 3 examines the planner's problem, while Section 4 analyzes the steady state solution of the laissez-faire economy and compares it with the optimal solution. In Section 5 we show that a policy that links pension benefits to the number of children is a sufficient device to decentralize the social optimum (as a single instrument). This pension policy restores the optimal incentives for individuals to have children, so that the optimal capital and the optimal population growth rate are achieved simultaneously when the payroll tax is properly chosen. We also show that other types of PAYG pension system, such as a Beveridgean or a Bismarckian system, are not useful to restore the first best.

\section{The Model}

We consider a two-period OLG model. The economy is constituted of couples, each one formed by one man and one woman. Men and women differ in their ability in the production process. It is assumed that both men and women are endowed with one unit of gender-specific labor. The production function includes three inputs, physical capital and two types of labor input:

$$
Y_{t}=F\left(K_{t}, L_{t}^{f}, L_{t}^{m}\right)
$$

with $K_{t}$ denoting the capital stock, $L_{t}^{f}$ the stock of female labor and $L_{t}^{m}$ the amount of male labor. For simplicity, capital is assumed to totally depreciate in the production process. 
The crucial assumption in order to have an endogenous demographic transition is that the production function $F(\cdot)$ is such that capital is more complementary to female labor than it is to male labor. This assumption can be justified, as in Galor and Weil (1996), by the fact that men have a comparative advantage in physical labor, which is less complementary to capital than mental labor. They therefore provide more physical labor than women, who have a comparative advantage in mental labor. This ensures that, as the economy develops and capital increases, the female wage -which, as will be seen later, constitutes the opportunity cost of having children- increases proportionately more than total household income -the sum of the two wages. Hence, independently of what the preferences towards children are, the substitution effect of an increase in wages dominates the income effect and households decide to have less children. This, in turn, further increases the stock of capital, producing a demographic transition.

In the first period of their life, men supply inelastically their unit of labor in the market, while women divide their unit of time between working in the market and raising children ${ }^{6}$. As the total amount of male labor, $L_{t}^{m}$, is equal to the number of working-age couples in the economy, assuming that the production function exhibits constant returns to scale, we can express it in per-couple terms as:

$$
y_{t}=f\left(k_{t}, l_{t}^{f}\right)
$$

with its derivatives $f_{k}\left(k_{t}, l_{t}^{f}\right)>0$ and $f_{l}\left(k_{t}, l_{t}^{f}\right)>0$, and where $y_{t}, k_{t}, l_{t}^{f}$ are respectively per-couple units of output, capital ${ }^{7}$ and female labor.

To endogenize fertility, we introduce a taste for children and a cost of children. First, we suppose individuals derive utility from the number of descendants they have. Individual preferences can be represented by the following utility function:

$$
U\left(n_{t}, c_{t}, d_{t+1}\right)=\gamma u\left(n_{t}\right)+(1-\gamma)\left[u\left(c_{t}\right)+\beta u\left(d_{t+1}\right)\right]
$$

where $u(\cdot)$ is increasing and concave in its argument, $\gamma \in[0,1]$ is a parameter reflecting the taste for children, $\beta \in[0,1]$ is the subjective discount factor, $n_{t}=\frac{N_{t+1}}{N_{t}}$ represents the number of children (expressed in terms of number of couples) that each couple has, while $c_{t}$ and $d_{t+1}$ are respectively the couple's consumption in the first and second period of life. The first derivatives of the utility function with respect to each argument can be written as $\gamma u^{\prime}\left(n_{t}\right)>0$, $(1-\gamma) u^{\prime}\left(c_{t}\right)>0,(1-\gamma) \beta u^{\prime}\left(d_{t+1}\right)>0$.

\footnotetext{
${ }^{6}$ We could think that women earn lower wages than men, hence have a lower opportunity cost of raising children; or, alternatively, we could think that women have a comparative advantage in childcare due to some natural reason. In any case, this assumption will permit to explain the observed drop in fertility together with the observed increase in female participation in the labor market. In section 5 we will see that this assumption has further implications for the analysis. Of course this is only valid if, as still happens in many countries, the role of the father in child care is much lower than the role of the mother. Needless to say, we are not advocating for this situation to continue but considering a fact that was present while fertility was falling.

${ }^{7}$ In the following we will use the term capital to refer to the per couple -or per male laborcapital stock.
} 
Second, we assume children are costly in terms of time. Each couple of children consumes a fraction $z$ of the woman's endowment of time. The inclusion of a time cost of children implies the endogeneity of female labor supply, as it introduces a trade-off between working and having children.

\section{The Planner's Problem}

In this section, we solve the planner's problem and describe how the optimal rate of population growth is determined. Following Samuelson (1975), we assume that the planner maximizes the utility of the representative agent at the steady state.

Definition 1 An optimal allocation at the steady state is a set of positive quantities $\left(c, d, n, k, l^{f}\right)$ that solve the following problem:

$$
\max _{c, d, n, k} \gamma u(n)+(1-\gamma)[u(c)+\beta u(d)]
$$

subject to the resource constraint of the economy:

$$
f\left(k, l^{f}\right)=c+\frac{d}{n}+n k
$$

where $l^{f}=1-z n$.

If it exists 8 , an interior optimal solution is characterized by the following optimality conditions:

$$
\begin{gathered}
\frac{u^{\prime}(c)}{u^{\prime}(d)}=\beta n \\
f_{k}\left(k, l^{f}\right)=n \\
\frac{\gamma}{1-\gamma} \frac{u^{\prime}(n)}{u^{\prime}(c)}+\frac{d}{n^{2}}=z f_{l}\left(k, l^{f}\right)+k \\
f\left(k, l^{f}\right)=c+\frac{d}{n}+n k \\
l^{f}=1-z n
\end{gathered}
$$

The first equation replicates the individual allocation of consumption across time. The second condition is the so-called golden rule, which determines the optimal stock of capital. Equation (5) is the first order condition determining the optimal number of children or population growth rate by equalizing the marginal benefit of children to their marginal cost. The former is given by the marginal

\footnotetext{
${ }^{8}$ As Deardorff (1976) first pointed out, this problem is not necessarily globally concave. In the following, we assume the existence of an interior optimal solution in the planner's problem, and in Appendix A we deal with this issue and show that, contrary to Samuelson's case, with endogenous fertility there exists the possibility of having an interior global maximum with Cobb-Douglas utility and production functions.
} 
utility provided by children to their parents -in terms of consumption- plus the intergenerational transfer effect $\left(\frac{d}{n^{2}}\right)$. This effect captures the fact that, when population grows, there are more working individuals to support each retired person, which reduces the relative cost of consumption of the old. The marginal cost of children for the planner is the loss in production due to the time cost of children plus the so-called capital dilution effect $(k)$, according to which the higher the population growth, the higher the investment requirement to keep a constant level of capital.

\section{Inefficiencies of the Laissez-Faire Economy}

\subsection{The Laissez-Faire Economy}

In the first period of their life, couples raise their children, supply labor in the labor market, consume and save. In the second period, they consume the products of their savings. The budget constraints of the couple are then given by:

$$
\begin{gathered}
c_{t}+s_{t}=w_{t}^{m}+w_{t}^{f}\left(1-z n_{t}\right) \\
d_{t+1}=R_{t+1} s_{t}
\end{gathered}
$$

with $w_{t}^{f}$ and $w_{t}^{m}$ being respectively the wages for female and male labor, $R_{t+1}$ the gross interest rate in period $t+1$ and $s_{t}$ denoting the savings made in period $t$.

Maximizing the utility function of a couple (2) subject to these two budget constraints gives the two following first order conditions:

$$
\begin{aligned}
& \frac{u^{\prime}\left(c_{t}\right)}{u^{\prime}\left(d_{t+1}\right)}=\beta R_{t+1} \\
& \frac{\gamma}{1-\gamma} \frac{u^{\prime}\left(n_{t}\right)}{u^{\prime}\left(c_{t}\right)}=z w_{t}^{f}
\end{aligned}
$$

Equation (10) determines the allocation of consumption across time and therefore the amount of savings. The second first order condition (11) determines the total amount of time devoted to child-raising by equalizing the marginal utility of children to their opportunity cost, both in terms of consumption. As noted above, the higher the female wage, the higher is the opportunity cost of children.

The competitive behavior of the representative firm leads to the equalization of factor prices to their marginal productivity:

$$
\begin{gathered}
R_{t}=f_{k}\left(k_{t}, l_{t}^{f}\right) \\
w_{t}^{f}=f_{l}\left(k_{t}, l_{t}^{f}\right) \\
w_{t}^{m}=f\left(k_{t}, l_{t}^{f}\right)-k_{t} f_{k}\left(k_{t}, l_{t}^{f}\right)-l_{t}^{f} f_{l}\left(k_{t}, l_{t}^{f}\right)
\end{gathered}
$$


Capital comes from savings in the previous period. The capital market equilibrium condition is therefore given by:

$$
k_{t+1} n_{t}=s_{t}
$$

Finally, the labor market equilibrium condition is:

$$
l_{t}^{f}=1-z n_{t}
$$

Definition 2 A steady state in the laissez-faire economy is a stationary path of variables $\left(c, d, n, s, k, l^{f}, w^{f}, w^{m}, R\right)$ with positive quantities verifying the following conditions:

$$
\begin{gathered}
\frac{u^{\prime}(c)}{u^{\prime}(d)}=\beta R \\
\frac{\gamma}{1-\gamma} \frac{u^{\prime}(n)}{u^{\prime}(c)}=z w^{f} \\
c+s=w^{m}+w^{f}(1-z n) \\
d=R s \\
l^{f}=1-z n \\
s=k n \\
R=f_{k}\left(k, l^{f}\right) \\
w^{f}=f_{l}\left(k, l^{f}\right) \\
w^{m}=f\left(k, l^{f}\right)-k f_{k}\left(k, l^{f}\right)-l^{f} f_{l}\left(k, l^{f}\right)
\end{gathered}
$$

Appendix B proves the existence of a unique steady state in the case of loglinear utility and Cobb-Douglas production and shows the transition path of capital and fertility towards its steady state values, illustrating the demographic transition.

\subsection{The external effects caused by fertility}

A comparison of the steady state solutions for the planner and the laissezfaire economy gives an intuition for the reason why the latter does not reach optimality. Using equations (22)-(25), we can rewrite (17)-(21) as:

$$
\begin{gathered}
\frac{u^{\prime}(c)}{u^{\prime}(d)}=\beta f_{k}\left(k, l^{f}\right) \\
\frac{\gamma}{1-\gamma} \frac{u^{\prime}(n)}{u^{\prime}(c)}=z f_{l}\left(k, l^{f}\right) \\
f\left(k, l^{f}\right)=c+\frac{d}{n}+n k
\end{gathered}
$$




$$
\begin{gathered}
\frac{d}{n f_{k}\left(k, l^{f}\right)}=k \\
l^{f}=1-z n
\end{gathered}
$$

Note that these five equations determine the same five variables as the planner's problem. The intertemporal allocation of consumption is the same for both steady states, as it is the resource constraint and the labor market equilibrium condition. However, the golden rule is not present in the laissez-faire solution, and the equation determining fertility is different. When choosing the number of children, couples do not take into account the capital dilution nor the intergenerational transfer effect.

As long as forward altruism is not perfect, in the sense that parents do not value the utility of their offspring, they are ignoring that their children will be productive in the next period. In other words, agents ignore that their children will need an amount of capital to produce -the capital dilution effect- and that the fact their children are alive will make labor relatively more abundant when they are old, implying that their consumption in the second period of life will be cheaper -the intergenerational transfer effect. This necessarily affects prices. First, the price of the more abundant factor -the wage- decreases. Second, the price of the more scarce factor -the interest rate, which is, in the competitive economy, the income left for the retired-increases. Couples are not aware of these price effects. So it seems clear that the fertility decision causes an externality that needs to be corrected.

Summarizing, apart from the well-known inefficiencies associated with capital accumulation, the laissez-faire economy fails to achieve the first best because the agents do not capture the effect of their children in the next period's production process, which is both positive (intergenerational transfer effect) and negative (capital dilution effect). We are now ready for the task -undertaken in the next section- of investigating whether a pension policy can induce agents to internalize these inefficiencies, leading the laissez-faire economy to the optimal solution.

\section{The Optimal Pension Policy}

As said above, understanding the kind of externality induced by the fertility decision and the channels through which it operates can help us to determine the structure of the corrective tax needed to internalize it. In this section we investigate the way to use pension policy as such a corrective tax.

First we analyze the interaction between the presently available PAYG pension policies and fertility: in Section 5.1 we analyze the effects of a pension policy with fixed monetary benefits (Beveridgean) and in Section 5.2 the effects of a pension formula that takes into account past contributions (Bismarckian). We show why these systems fail to correct the inefficiencies associated with the laissez-faire economy. By contrast, in Section 5.3, a system that links pensions to the contributions of own children is shown to provide the optimal incentives 
for couples to choose both the first best capital stock and the first best fertility rate.

\subsection{A Beveridgean PAYG Pension System}

Suppose that we introduce a pension system that gives a constant pension to each retired agent. The system is implemented as follows. A proportional taxation rate, $\tau_{t}$, is levied on male labor income ${ }^{9}$ and each retired person at $t$ receives a pension benefit $p_{t}$ coming from contributions in the same period. For convenience, we will refer to this type of pension system as Beveridgean PAYG pension system.

Definition 3 A steady state competitive equilibrium under a Beveridgean PAYG pension system is a transfer system $(p, \tau)$ satisfying:

$$
p=n \tau w^{m}
$$

and a vector of variables $\left(c, d, n, s, l^{f}, k, w, R\right)$ satisfying (17), (18), (21), (22), (23), (24), (25) and:

$$
\begin{gathered}
c+s=w^{m}(1-\tau)+w^{f}(1-z n) \\
d=s R+p
\end{gathered}
$$

Equation (31) is the social security system's budget constraint at the steady state. Observe in (33) that couples perceive their pension as a fixed amount of money, not being aware that their pension comes from the contributions of their children. Suppose that the government fixes the value of the payroll tax $\tau$ and pension benefits are determined endogenously from equation (31). The government can choose the value of the contribution rate such that the golden rule is attained. However, as stated in the following proposition, this policy cannot decentralize the first best, as it is not able to ensure simultaneously the optimal capital stock and the optimal rate of population growth.

Proposition 4 A Beveridgean PAYG pension system cannot be used to decentralize the social optimum.

Proof. Using (22), (23), (25) and (31), we can rewrite (33) as:

$$
\frac{d}{f_{k}(k, l)}-\tau \frac{n}{f_{k}(k, l)}\left[f\left(k, l^{f}\right)-k f_{k}\left(k, l^{f}\right)-l^{f} f_{l}\left(k, l^{f}\right)\right]=k n
$$

Suppose the government sets the tax rate so as to induce the level of capital satisfying the golden rule. This value of the payroll tax, obtained from equation (34) by setting $f_{k}(k, l)=n$, is given by:

$$
\tau=\frac{1}{\left[f\left(k, l^{f}\right)-k n-l^{f} f_{l}\left(k, l^{f}\right)\right]}\left[\frac{d}{n}-k n\right]
$$

\footnotetext{
${ }^{9}$ This does not produce any distortion in the choice of labor, since male labor supply is inelastic. The results in this section would still hold if both types of labor were taxed.
} 
However, equation (18), i.e. the couple's first order condition with respect to fertility, is still different from the optimal one given by (5). Thus the optimal values of the capital stock and the population growth rate are not achieved. Alternatively, if $\tau$ is chosen so as to reach the optimal $k$, neither the golden rule nor the optimal $n$ would be attained. And something similar would happen if the payroll tax was chosen so as to reach the optimal population growth rate. Therefore, another instrument is required to restore the first best.

This result is not surprising as far as the Beveridgean pension policy has no corrective effects on fertility. It simply crowds out capital accumulation, but it does not introduce the right incentives for couples to choose the number of children in an optimal way.

\subsection{A Bismarckian PAYG Pension System}

Although the previous analysis is interesting as a starting point, one might point out that in reality individuals do not perceive their pension as fixed. In fact, in most OECD countries, pension benefits are defined as a replacement rate on past wages. This replacement rate often depends on labor participation, as benefits are a function of the number of years of contribution to the system. Moreover, in many countries, recent reforms of the pension system tend to increase the proportionality between contribution years and pension benefits. In the following we analyze a pension system where benefits are defined according to the following pension formula:

$$
p_{t+1}=\theta_{t+1}\left[w_{t}^{m}+w_{t}^{f}\left(1-z n_{t}\right)\right]
$$

where $\theta_{t+1}$ is the gross replacement rate on the couple's labor earnings. Then, from the couple's point of view, the pension is positively related to female labor force participation. As a result, the pension will be negatively related to fertility, so that, with respect to the Beveridgean pension formula, we may expect more interaction with fertility.

The social security system's budget constraint, which must be balanced every period, can be expressed as:

$$
\theta_{t+1}\left[w_{t}^{m}+w_{t}^{f}\left(1-z n_{t}\right)\right]=n_{t} \tau_{t+1}\left[w_{t+1}^{m}+w_{t+1}^{f}\left(1-z n_{t+1}\right)\right]
$$

We refer to this system as Bismarckian PAYG pension system. Under such a system, which is assumed to tax all wages ${ }^{10}$, the first order conditions of the couple's maximization problem are:

$$
\frac{u^{\prime}\left(c_{t}\right)}{u^{\prime}\left(d_{t+1}\right)}=\beta R_{t+1}
$$

\footnotetext{
${ }^{10} \mathrm{As}$ it corresponds to reality, i.e. female labor is also taxed by the social security administration. Again, the main result that the system cannot decentralize the social optimum does not change if only male labor is taxed.
} 


$$
\frac{\gamma}{1-\gamma} \frac{u^{\prime}\left(n_{t}\right)}{u^{\prime}\left(c_{t}\right)}=z w_{t}^{f}\left[\left(1-\tau_{t}\right)+\frac{\theta_{t+1}}{R_{t+1}}\right]
$$

Factor prices are still given by (12), (13), (14), and the equilibrium conditions for the labor market and the capital market by (15) and (16).

Definition 5 A steady state competitive equilibrium under a Bismarckian PAYG pension system is a transfer system $(p, \theta, \tau)$ satisfying:

$$
\begin{gathered}
p=\theta\left[w^{m}+w^{f}(1-z n)\right] \\
\theta=n \tau
\end{gathered}
$$

and a vector of variables $\left(c, d, n, s, l^{f}, k, w^{f}, w^{m}, R\right)$ satisfying (17), (21), (22), (23), (24), (25) and:

$$
\begin{gathered}
\frac{\gamma}{1-\gamma} \frac{u^{\prime}(n)}{u^{\prime}(c)}=z w^{f}\left[(1-\tau)+\frac{\theta}{R}\right] \\
c+s=\left[w^{m}+w^{f}(1-z n)\right](1-\tau) \\
d=s R+\theta\left[w^{m}+w^{f}(1-z n)\right]
\end{gathered}
$$

As can be seen from equation (41), the existence of a Bismarckian pension system affects the fertility decision in two ways. On the one hand, the payroll tax reduces the opportunity cost of children in terms of net wage, having a positive effect on fertility. On the other hand, the social security system increases such a cost by reducing second period consumption (through lower pension benefits), having a negative effect on the choice of the number of children. We could then expect that these two opposite effects on the fertility decision would allow to internalize the capital dilution and the intergenerational transfer effects. However, it is not the case, as explained in the following proposition.

Proposition 6 A Bismarckian PAYG pension system cannot be used to decentralize the planner's optimum.

Proof. Suppose that the government chooses the value of the replacement rate, and then determines the payroll tax according to equation (40) and pension benefits according to (39) ${ }^{11}$. Using (24) and (40), equation (41) can be written as:

$$
\frac{\gamma}{1-\gamma} \frac{u^{\prime}(n)}{u^{\prime}(c)}=z f_{l}\left(k, l^{f}\right)\left[1-\frac{\theta}{n}+\frac{\theta}{R}\right]
$$

Therefore, if the payroll tax is chosen so that the golden rule is satisfied, i.e. $R=n$, the last two terms of the previous expression cancel out and the first order condition with respect to $n$ becomes:

$$
\frac{\gamma}{1-\gamma} \frac{u^{\prime}(n)}{u^{\prime}(c)}=z f_{l}\left(k, l^{f}\right)
$$

\footnotetext{
${ }^{11}$ Results would not change if the government fixed the contribution rate instead and the replacement rate was adjusted.
} 
which always differs from the optimal fertility decision, unless by chance the capital dilution and intergenerational transfer effects cancel each other in the planner's solution and thus disappear. However, in such a case the optimal pension policy would be to have no transfer system. Hence, this pension policy cannot be used to decentralize the first best.

We can also remark that, in addition to the two direct effects on the couple's fertility decision, the introduction of a payroll tax produces several general equilibrium effects by affecting capital accumulation and therefore factor prices. Taking into account all these effects, the sign of the impact of the pension system on fertility at the steady state is ambiguous and crucially depends on the benefit formula as well as on preferences and technology. It can be proven that with a Cobb-Douglas production function and a log-linear utility function, an increase in the size of the Bismarckian pension system increases the steady state fertility level, while it decreases the steady state capital stock ${ }^{12}$.

\subsection{A PAYG System Linking Pensions to the Number of Children}

So far in this section we have seen that the existing PAYG pension systems are not able to decentralize the social optimum. The reason is, going back to the discussion in Section 4.2, that those systems do not properly inform agents on the size and direction of the intergenerational transfer effect and the capital dilution effect. It seems that what we need is agents to be aware that their children will be productive in the next period and that this will affect prices. As we argued in the Introduction, an intuitive reform of social security to resolve the pension crisis would be to change the pension system so that it linked somehow benefits to the number of children.

Suppose we introduce a pension formula in which pension benefits are distributed proportionally to fertility behavior as well as to the level of future wages -i.e. proportionally to the children's contribution to the pension scheme. As we did in Section 5.1, to avoid any distortions on the labor supply choice, we assume this system is financed by proportional taxation on male labor income only ${ }^{13}$. We refer to this type of pension system as PAYG pension system with fertility link. In the following we analyze whether such a transfer system achieves the social optimum, so that both the optimal capital stock and the optimal population growth rate are achieved simultaneously and the golden rule is attained. The answer is positive: this PAYG pension system can decentralize the first best.

With such a pension policy, the budget constraints of the couple become:

$$
c_{t}+s_{t}=w_{t}^{m}\left(1-\tau_{t}\right)+w_{t}^{f}\left(1-z n_{t}\right)
$$

\footnotetext{
${ }^{12}$ As the utility is log-linear, the substitution and income effects cancel each other and the pension system only affects the fertility decision through general equilibrium effects. The payroll tax crowds out capital and pushes the economy back to an earlier stage of the demographic transition. See Abío (2002).

${ }^{13}$ It is therefore equivalent to using a lump-sum tax, which should be used if male labor was also elastically supplied. We come back on this issue later in this section.
} 


$$
d_{t+1}=s_{t} R_{t+1}+w_{t+1}^{m} \tau_{t+1} n_{t}
$$

where $\tau_{t}$ is the social security contribution rate, fixed by the government. As can be seen in (45), the pension formula exactly replicates the budget constraint of the PAYG pension system, given by:

$$
p_{t+1}=n_{t} w_{t+1}^{m} \tau_{t+1}
$$

Hence, this pension policy provides couples with the information that their pensions depend on the productivity of their children as well as on the population growth rate.

The first order conditions of the couple's maximization program expressed at the steady state become:

$$
\begin{gathered}
\frac{u^{\prime}(c)}{u^{\prime}(d)}=\beta R \\
\frac{\gamma}{1-\gamma} \frac{u^{\prime}(n)}{u^{\prime}(c)}+\frac{w^{m} \tau}{R}=z w^{f}
\end{gathered}
$$

Definition 7 A steady state competitive equilibrium under a PAYG pension system with fertility link is a transfer system $(p, \tau)$ satisfying:

$$
p=w^{m} \tau n
$$

and a vector of variables $\left(c, d, n, s, k, l^{f}, w^{f}, w^{m}, R\right)$ with positive quantities verifying (46), (47), (21), (22), (23), (24), (25) and:

$$
\begin{gathered}
c+s=w^{m}(1-\tau)+w^{f}(1-z n) \\
d=s R+w^{m} \tau n
\end{gathered}
$$

We assume the government fixes the payroll tax and then determines pension benefits according to (48).

Proposition 8 In a model with endogenous fertility, if an interior optimal allocation exists, a PAYG social security system with fertility link decentralizes the first best if the payroll tax satisfies:

$$
\tau^{*}=\frac{\frac{d}{n}-k n}{f\left(k, l^{f}\right)-k n-l^{f} f_{l}\left(k, l^{f}\right)}
$$

Proof. Isolating the term $w^{m} \tau$ from (50), (47) can be written as:

$$
\frac{\gamma}{1-\gamma} \frac{u^{\prime}(n)}{u^{\prime}(c)}+\frac{d}{n R}=z w^{f}+\frac{s}{n}
$$

Substituting (22)-(25) into this new expression and in (46), (49) and (50), we can rewrite these four equations as:

$$
\frac{u^{\prime}(c)}{u^{\prime}(d)}=\beta f_{k}\left(k, l^{f}\right)
$$




$$
\begin{gathered}
\frac{\gamma}{1-\gamma} \frac{u^{\prime}(n)}{u^{\prime}(c)}+\frac{d}{n f_{k}\left(k, l^{f}\right)}=z f_{l}\left(k, l^{f}\right)+k \\
f\left(k, l^{f}\right)=c+\frac{d}{n}+k n \\
d=f_{k}\left(k, l^{f}\right) k n+\left[f\left(k, l^{f}\right)-k f_{k}\left(k, l^{f}\right)-l^{f} f_{l}\left(k, l^{f}\right)\right] \tau n
\end{gathered}
$$

The first three equations are identical to the planner's first order conditions (3), (5) and (6), once we take into consideration (4), and (21) is the same as (7). Hence, this pension policy provides the right incentives to choose the fertility rate optimally. The optimal value of $\tau$ can then be obtained from (55) once the golden rule has been introduced in that equation:

$$
d=k n^{2}+\left[f\left(k, l^{f}\right)-k n-l^{f} f_{l}\left(k, l^{f}\right)\right] \tau^{*} n
$$

Isolating the payroll tax in the previous expression, equation (51) is obtained.

The reason for such a policy to constitute a single instrument to reach the first best comes from the fact that such a pension system introduces the links that are missing in the couple's fertility and savings decision. As can be seen in (45), this policy introduces a specific link between $n$ and $d$ and between $n$ and $k$. It introduces a positive link between consumption of the old and the fertility decision (internalizing the intergenerational transfer effect). Moreover, it affects capital accumulation because it introduces another way of saving through having children. This allows the capital dilution effect to be internalized. Hence, for any value of the payroll tax, the proposed policy corrects the divergences from the optimal fertility decision. The value of the payroll tax can then be chosen so as to restore the optimal capital stock, accomplishing the golden rule. Since the individual allocation rule of consumption over the life-cycle is the same as the optimal one, there is no need for another instrument to allocate consumption optimally. Thus, for any interior optimal allocation there exists a transfer system $\tau^{*}$ such that this allocation is a steady state intertemporal equilibrium with perfect foresight.

Note that the sign of the transfer is not necessarily positive. Since one effect is positive -intergenerational transfer effect- and the other one is negative capital dilution effect-, the sign of the transfer depends on the balance of the two. The weight of each effect depends on the parameters of the production and utility functions as well as on the size of $n$. A negative value for $\tau^{*}$ implies a transfer mechanism from the old to the young that would no longer be a pension system. Note also that this system works as long as no additional distortions on fertility are introduced. In particular, it is necessary to avoid taxing female labor so that the pension policy does not affect the fertility decision through a decline in the female net wage -as we had in the Bismarckian system ${ }^{14}$. In Peters (1995) there is an additional source of external effects, as human capital accumulation is the source of growth. Hence, two corrective taxes are required

\footnotetext{
${ }^{14}$ If the cost of children is a fixed monetary amount, instead of a time cost, then female labor supply can be taxed without producing any distortions on the fertility choice.
} 
to decentralize the first best. First, a corrective tax on educational expenditures, which is unambiguously negative (implying a subsidy); second, a tax on other expenditures related to child care, which has an ambiguous sign depending on similar factors to our payroll tax.

Finally, remark that this kind of policy could be implemented in different ways. For example, designing a transition to a partially funded system -as proposed by Sinn (2000)- in which pension benefits were linked to the fertility behavior of individuals. Alternatively, a compensatory family allowance equivalent to the present value of the children's future contribution to the pension scheme could be given to parents while they are raising children. In this line, Schweizer (1996) shows that a PAYG-financed family allowance combined with a PAYG-financed pension system leads the economy to the social optimum as long as the collected revenue is equally divided between the two systems.

\section{Conclusion}

In order to shed some light on the current debate over the pension reform required by the drop in fertility, this paper approaches the issue of optimality of the pension policy in an endogenous fertility setting. The purpose of the paper was not to characterize a full set of policies and design a transition from the present PAYG pension system to another, but rather to contribute to this debate by clarifying the interaction between pension policies and the fertility decision.

By differentiating between female and male labor, the model both highlights the relation between female labor supply and the fertility decision and produces an endogenous demographic transition. A comparison of the planner steady state solution with the laissez-faire solution confirms that in this setting the competitive economy fails to achieve the first best as it usually happens in OLG models. The reason for this divergence is analyzed, concluding that in addition to the inefficiencies associated with the choice of savings, the fertility decision produces external effects. This is mainly because, in the absence of perfect forward altruism, parents fail to perceive that their children will be future producers: they ignore that capital and labor available in the next period will change as a result of their choice of the number of children, affecting prices and the return of transferring resources between generations.

In order to decentralize the social optimum, different pension policies are analyzed which aim at making couples internalize the effects of their fertility choice as well as to induce the optimal level of capital. First we show that the systems which are more commonly used at the moment fail to lead the economy to the first best: a Beveridgean system with constant pension benefits has no direct effect on fertility, while a Bismarckian system where benefits are proportional to labor force participation has both a positive and a negative effect on fertility that nevertheless do not have the appropriate size to correct the externality. By contrast, a simple way to make the non perfectly altruistic parents aware of the next period productivity of their offspring is giving them 
the opportunity to save in children. This can be achieved through a PAYG pension policy where benefits are proportional to the number of children as well as to future wages.

Finally, remark that in addition to restore the social optimum, such a transfer system is attractive as it suggests a pension policy that could solve the financial crisis of the pension system, eliminating its dependency on demographic stability. Other proposals to reform the pension system by taking into account the interaction between fertility and the pension policy could be to use family

allowances or to switch to a mixed funded system.

\section{References}

[1] Abío, G. (2002): The Pay-As-You-Go Pension System Reform: Considering the Role of Fertility, Ph. D. Thesis, Universitat de Barcelona.

[2] Becker, G., K.M. Murphy and R. Tamura (1990): Human Capital, Fertility and Economic Growth, Journal of Political Economy 98, pp. S12-S37.

[3] Bental, B. (1989): The Old Age Security Hypothesis and Optimal Population Growth, Journal of Population Economics 1, pp. 285-301.

[4] Cigno, A. (1993): Intergenerational Transfers Without Altruism, European Journal of Political Economy 9, pp. 505-518.

[5] de la Croix, D. and P. Michel (2002): A Theory of Economic Growth. Dynamics and Policy in Overlapping Generations, Cambridge University Press.

[6] Deardorff, A.V. (1976): The Optimum Growth Rate for Population: Comment, International Economic Review 17, pp. 510-515.

[7] Diamond, P. A. (1965): National Debt in a Neoclassical Growth Model, American Economic Review 55 (5), pp. 1126-1150.

[8] Eckstein, Z. and K.I. Wolpin (1985): Endogenous Fertility and Optimal Population Size, Journal of Public Economics 27, pp. 93-106.

[9] Galor, O. and D.N. Weil (1996): The Gender Gap, Fertility and Growth, American Economic Review 86 (3), pp. 374-386.

[10] Galor, O. and D.N. Weil (2000): Population, Technology and Growth: from the Malthusian Regime to the Demographic Transition, American Economic Review, 90 (4), pp. 806-828.

[11] Kolmar, M. (1997): Intergenerational Redistribution in a Small Open Economy with Endogenous Fertility, Journal of Population Economics 10, pp. 161-183. 
[12] Kolmar, M. (2001): Optimal Intergenerational Redistribution in a TwoCountry Model with Endogenous Fertility, Public Choice 106, pp. 23-51.

[13] Michel, Ph. and P. Pestieau (1993): Population Growth and Optimality. When does serendipity hold?, Journal of Population Economics 6, pp. 353362 .

[14] Peters, W. (1995): Public Pensions, Family Allowances and Endogenous Demographic Change, Journal of Population Economics 8, pp. 161-183.

[15] Samuelson, P. A. (1975): The Optimum Growth Rate for Population, International Economic Review 16, pp. 531-538.

[16] Samuelson, P. A. (1976), The Optimum Growth Rate for Population: Agreements and evaluations, International Economic Review 17, pp. 516525 .

[17] Schweizer, U. (1996): Endogenous Fertility and the Henry George Theorem, Journal of Public Economics 61, pp. 209-228.

[18] Sinn, H.-W. (2000): Why a Funded Pension System is Useful and Why it is not Useful, International Tax and Public Finance 4/5, Vol. 7, pp. 389-410.

[19] Wigger, B. U. (1999): Pay-As-You-Go Financed Public Pensions in a Model of Endogenous Growth and Fertility, Journal of Population Economics 12, pp. $625-640$. 


\section{A Interiority of the Optimal Solution}

Deardorff (1976) shows that, for a wide range of utility and production functions, Samuelson's (1975) problem of finding the optimum growth rate for population in Diamond's OLG model does not have an interior global maximum. For instance, with a Cobb-Douglas production function and a log-linear utility function, there exists no interior solution to the planner's problem when capital depreciation is total, while there may only exist an interior minimum if capital depreciation is lower than 1. Michel and Pestieau (1993), using CES utility and production functions and assuming total depreciation of capital, analyze the conditions guaranteeing the existence of an interior solution. They conclude that, in order to have such a solution, there must exist complementarity between labor and capital in production. Alternatively, if the production function is of the Cobb-Douglas type, complementarity between first and second period consumption in preferences is required. In all other cases, the optimal population growth rate is a corner solution. Schweizer (1996) deals with this problem in a context with endogenous fertility. He compares Samuelson's model with local public goods models, and insists on the fact that the planner's first order conditions are not sufficient for optimality.

In the following we analyze whether it is possible to have an interior global maximum in the planner's problem in our framework. The existence of an interior solution depends on the shape of the utility and production functions. After giving necessary and sufficient conditions for the existence of such a solution for general preferences and technology, we focus on the case of a log-linear utility function and a Cobb-Douglas production function.

\section{A.1 The general case}

A necessary condition to have an interior global maximum is that there is a solution to the planner's set of first order conditions. In addition, the Hessian matrix corresponding to the planner's problem evaluated at such a critical point must be negative semidefinite; this guarantees that this point is a local maximum. A sufficient condition that ensures that the maximum is unique and global is that the planner's objective is strictly concave, i.e. that the Hessian matrix is negative definite at all points. In order to determine sufficient conditions guaranteeing this result, we impose the following assumptions on the utility and production functions:

$$
\begin{aligned}
& \text { - } U_{i}(\cdot)>0, U_{i i}(\cdot)<0, U_{i j}(\cdot)=0, \quad \forall i, j=n, c, d, \quad i \neq j . \\
& \text { - } f_{k}(\cdot)>0, f_{l}(\cdot)>0, f_{k k}(\cdot)<0, f_{l l}(\cdot)<0, f_{k l}(\cdot)=f_{l k}(\cdot)>0 .
\end{aligned}
$$

We first reduce two dimensions of the problem by eliminating variables $d$ and $l^{f}$, using the resource constraint. Hence the planner's objective is expressed as $U(c, d(k), n)$ and the production function as $f\left(k, l^{f}(n)\right)$. The Hessian matrix 
can be written as:

$$
H=\left[\begin{array}{ccc}
\frac{\partial U^{2}}{\partial^{2} c} & \frac{\partial U^{2}}{\partial c \partial k} & \frac{\partial U^{2}}{\partial c \partial n} \\
\frac{\partial U^{2}}{\partial c \partial k} & \frac{\partial U^{2}}{\partial^{2} k} & \frac{\partial U^{2}}{\partial n \partial k} \\
\frac{\partial U^{2}}{\partial c \partial n} & \frac{\partial U^{2}}{\partial n \partial k} & \frac{\partial U^{2}}{\partial^{2} n}
\end{array}\right]
$$

We know this matrix is negative definite if the first and third order principal minors are negative and the second order ones are positive. Given the assumptions made on preferences, some of this minors have the right sign. For the rest, we have to find necessary or sufficient conditions. The following is a sufficient condition on the utility function which ensures that the fifth principal minor is positive, i.e. $\frac{\partial U^{2}}{\partial^{2} c} \frac{\partial U^{2}}{\partial^{2} n}-\left(\frac{\partial U^{2}}{\partial c \partial n}\right)^{2}>0$ :

$$
-2 U_{d} U_{d d} d-\left(U_{d}\right)^{2}>0
$$

which is always satisfied in the case of log-linear utility.

On the other hand, the following sufficient conditions on the production function ensure that the sixth principal minor is positive, i.e. $\frac{\partial U^{2}}{\partial^{2} k} \frac{\partial U^{2}}{\partial^{2} n}-\left(\frac{\partial U^{2}}{\partial n \partial k}\right)^{2}>0$ :

$$
\begin{gathered}
0 \leq f_{k}-n<n \\
\underbrace{2 \underbrace{\left(f_{n}-k\right)}_{<0} n \underbrace{f_{k k}}_{<0}>\underbrace{\left(f_{k}-2 n\right)\left(2 f_{k n} n+f_{k}-2 n\right)}_{>0 \text { if condition }(57) \text { above holds }}}_{>0}
\end{gathered}
$$

Finally, the seventh principal minor corresponds to the determinant of the whole Hessian matrix and is more complex. The following is a necessary condition for its determinant to be negative:

$$
\begin{aligned}
& \underbrace{+}_{d n f_{k k}[U_{n n}\left(U_{c c}+n^{2} U_{d d}\right)+U_{d d} U_{c c}\left(f_{n} n+\frac{d}{n}-k n\right)^{2}+\underbrace{\left(-2 U_{d} U_{d d} d-\left(U_{d}\right)^{2}\right)}_{>0 \text { if condition (56) holds }}} \\
& <0 \text { if condition (56) above holds } \\
& +\underbrace{U_{c c}\left(U_{d}\right)^{2} \underbrace{\left[2 f_{k k} n\left(f_{n}-k\right)-\left(f_{k}-2 n\right)\left(2 f_{k n} n+f_{k}-2 n\right)\right]}_{>0 \text { if conditions (57) and (58) above hold }}}_{<0 \text { if conditions (57) and (58) hold }}+U_{d d} U_{c c} n\left(f_{k}-n\right) \cdot \\
& {[\left(f_{k}-n\right)\left(U_{n n} n+U_{d}\left[f_{n n} n^{2}-2 \frac{d}{n}\right]\right)-2 U_{d} n \underbrace{\left(f_{n} n+\frac{d}{n}-k n\right)}_{?}\left(f_{k n}-1\right)]+} \\
& +\underbrace{\left[-U_{d d}\left(U_{d}\right)^{2} n^{4}\left(1-2 f_{k n}\right)\right]}_{>0}<0
\end{aligned}
$$


Hence a sufficient condition that guarantees that the objective of the planner is concave is that conditions (56), (57), (58) and (59) are satisfied.

\section{A.2 The case of a log-linear utility function and a Cobb- Douglas production function}

In such a case, the problem is drastically simplified since the indirect utility function can be expressed as a function of $n$ only. Preferences and technology are assumed to satisfy:

$$
\begin{gathered}
U_{t}\left(n_{t}, c_{t}, d_{t+1}\right)=\gamma \log \left(n_{t}\right)+(1-\gamma)\left[\log \left(c_{t}\right)+\beta \log \left(d_{t+1}\right)\right] \\
f\left(k_{t}, l_{t}\right)=A k_{t}^{\alpha}\left(l_{t}^{f}\right)^{1-\alpha}+B
\end{gathered}
$$

with $A>0$ and $B>0$. Observe that this production function allows a demographic transition to be generated ${ }^{15}$ but represents a strong assumption as it implies that male labor is not complementary to capital. It however strongly eases the analytical resolution.

For these specific functions, using the first order conditions of the planner's problem, we can express $c, d$ and $k$ as a function of $n$ only:

$$
\begin{gathered}
k=k(n)=(1-z n)\left(\frac{A \alpha}{n}\right)^{\frac{1}{1-\alpha}} \\
c=c(n)=\frac{1}{1+\beta}\left[\frac{1-\alpha}{\alpha}(A \alpha)^{\frac{1}{1-\alpha}}(1-z n) n^{\frac{-\alpha}{1-\alpha}}+B\right] \\
d=d(n)=\beta n \frac{1}{1+\beta}\left[\frac{1-\alpha}{\alpha}(A \alpha)^{\frac{1}{1-\alpha}}(1-z n) n^{\frac{-\alpha}{1-\alpha}}+B\right]
\end{gathered}
$$

Hence we can write the following indirect utility function:

$$
V(n)=\gamma \log (n)+(1-\gamma)[\log (c(n))+\beta \log (d(n))]
$$

which has the following limit values:

$$
\lim _{n \rightarrow 0} V(n)= \begin{cases}-\infty & \text { if } \alpha<\widetilde{\alpha}_{1} \\ +\infty & \text { if } \alpha>\widetilde{\alpha}_{1} \\ I & \text { if } \alpha=\widetilde{\alpha}_{1}\end{cases}
$$

with

$$
\widetilde{\alpha}_{1} \equiv \frac{\gamma+\beta(1-\gamma)}{1+2 \beta(1-\gamma)}
$$

and

$$
I \equiv \log \left(\beta^{\beta(1-\gamma)} A^{1+2 \beta(1-\gamma)} \frac{(1-\gamma)^{(1+\beta)(1-\gamma)}[\gamma+\beta(1-\gamma)]^{\gamma+\beta(1-\gamma)}}{[1+2 \beta(1-\gamma)]^{1+2 \beta(1-\gamma)}}\right)
$$

\footnotetext{
${ }^{15}$ Recall that the only condition required is that female labor is more complementary to capital than male labor is. See also Appendix B.
} 
while

$\lim _{n \rightarrow 1 / z} V(n)=[\gamma+\beta(1-\gamma)] \log \left(\frac{1}{z}\right)+(1-\gamma)(1+\beta) \log \left(\frac{\beta}{1+\beta}\right)+\beta(1-\gamma) \log \beta$

is a constant.

Second, taking the first derivative of $V(n)$ and grouping terms together we obtain:

$V^{\prime}(n)=\frac{[\gamma+\beta(1-\gamma)]}{n}-(1-\gamma)(1+\beta)\left(\frac{A \alpha}{n}\right)^{\frac{1}{1-\alpha}} \frac{1+z n\left(\frac{1-2 \alpha}{\alpha}\right)}{\left[\frac{1-\alpha}{\alpha}(A \alpha)^{\frac{1}{1-\alpha}}(1-z n) n^{\frac{-\alpha}{1-\alpha}}+B\right]}$

which can also be written as:

$$
V^{\prime}(n)=\underbrace{\frac{B[\gamma+\beta(1-\gamma)]}{n^{\frac{1}{1-\alpha}}\left[\frac{1-\alpha}{\alpha}(A \alpha)^{\frac{1}{1-\alpha}}(1-z n) n^{\frac{-\alpha}{1-\alpha}}+B\right]}}_{>0} g(n)
$$

where

$$
g(n) \equiv n^{\frac{\alpha}{1-\alpha}}-\Gamma n+\Theta
$$

with

$$
\Gamma \equiv \frac{z(A \alpha)^{\frac{1}{1-\alpha}}[1+2 \beta(1-\gamma)-\alpha[1+2 \beta(1-\gamma)+(1-\gamma)(1+\beta)]]}{\alpha B[\gamma+\beta(1-\gamma)]}
$$

and

$$
\Theta \equiv \frac{(A \alpha)^{\frac{1}{1-\alpha}}[\gamma+\beta(1-\gamma)-\alpha[1+2 \beta(1-\gamma)]]}{\alpha B[\gamma+\beta(1-\gamma)]}
$$

It can be shown that $\Gamma>0$ iff $\alpha<\widetilde{\alpha}_{2} \equiv \frac{1+2 \beta(1-\gamma)}{1+2 \beta(1-\gamma)+(1-\gamma)(1+\beta)}>1 / 2$ and $\Theta>0$ iff $\alpha<\widetilde{\alpha}_{1}<\widetilde{\alpha}_{2}$.

Note also that:

$$
\lim _{n \rightarrow 0} V^{\prime}(n)= \begin{cases}+\infty & \text { if } \alpha \leq \widetilde{\alpha}_{1} \\ -\infty & \text { if } \alpha>\widetilde{\alpha}_{1}\end{cases}
$$

The function $g(n)$ can be used to analyze the critical points of $V(n)$. Assuming $\alpha<1 / 2, \Gamma$ is always positive and $g(n)$ has a maximum given by:

$$
\widehat{n}=\left[\frac{1-\alpha}{\alpha} \Gamma\right]^{-\frac{1-\alpha}{1-2 \alpha}}
$$

On the other hand, the function $g(n)$ has the following limit values:

$$
\lim _{n \rightarrow 0} g(n)=\Theta
$$

and

$$
\lim _{n \rightarrow 1 / z} g(n)=\left(\frac{1}{z}\right)^{\frac{\alpha}{1-\alpha}}-\frac{(A \alpha)^{\frac{1}{1-\alpha}}}{B[\gamma+\beta(1-\gamma)]}\left[\gamma+\beta(1-\gamma)+\frac{1-2 \gamma}{\alpha}\right]
$$


Figure 1: Shape of $g(n)$

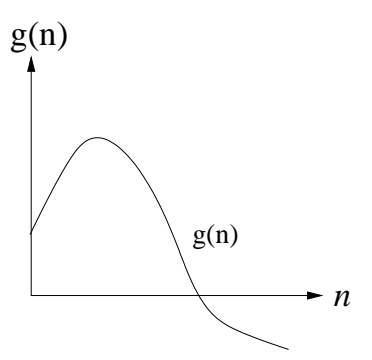

(a) $\alpha \leq \widetilde{\alpha}_{1}$
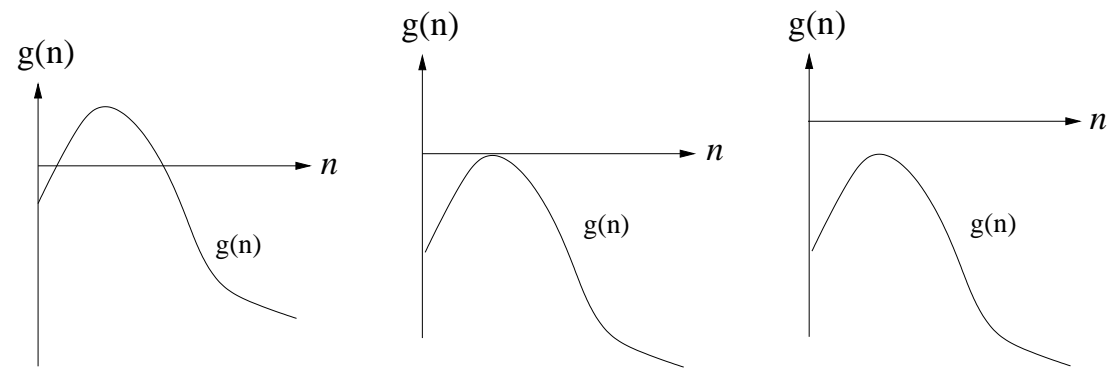

(b) $\widetilde{\alpha}_{1}<\alpha<1 / 2$

which is negative under the sufficient condition that:

$$
z>z_{\min } \equiv \frac{1}{\alpha A^{1 / \alpha}}\left(\frac{B[\gamma+\beta(1-\gamma)]}{(1+\beta)(1-\gamma)(1-\alpha)}\right)^{\frac{1-\alpha}{\alpha}}
$$

This condition guarantees that $z n^{*}<1$.

Hence, two cases can be distinguished:

- If $\alpha \leq \widetilde{\alpha}_{1}$ and $z>z_{\min }, \Theta \geq 0, \Gamma>0$ and $g(n)$ has one root for $n \in[0,1 / z]$. This is depicted in panel (a) of Figure 1. Hence, $V(n)$ has one critical point. The utility function first increases, reaches a maximum and then decreases, as represented graphically in panel (a) of Figure 2.

- If $\widetilde{\alpha}_{1}<\alpha<1 / 2, \Theta<0$ but $\Gamma>0$, and $g(n)$ can have one, two or no roots depending on the values of the parameters, as shown in panel (b) of Figure 1. The utility function starts decreasing, as can be seen in panels (b) and (c) of Figure 2. Depending on parameter values, utility may always decrease (in case $g(n)$ has no root) with the possibility of having an inflexion point (in case $g(n)$ has one root) or it may have first a local minimum and then a local maximum (in case $g(n)$ has two roots). 
Figure 2: Shape of $V(n)$

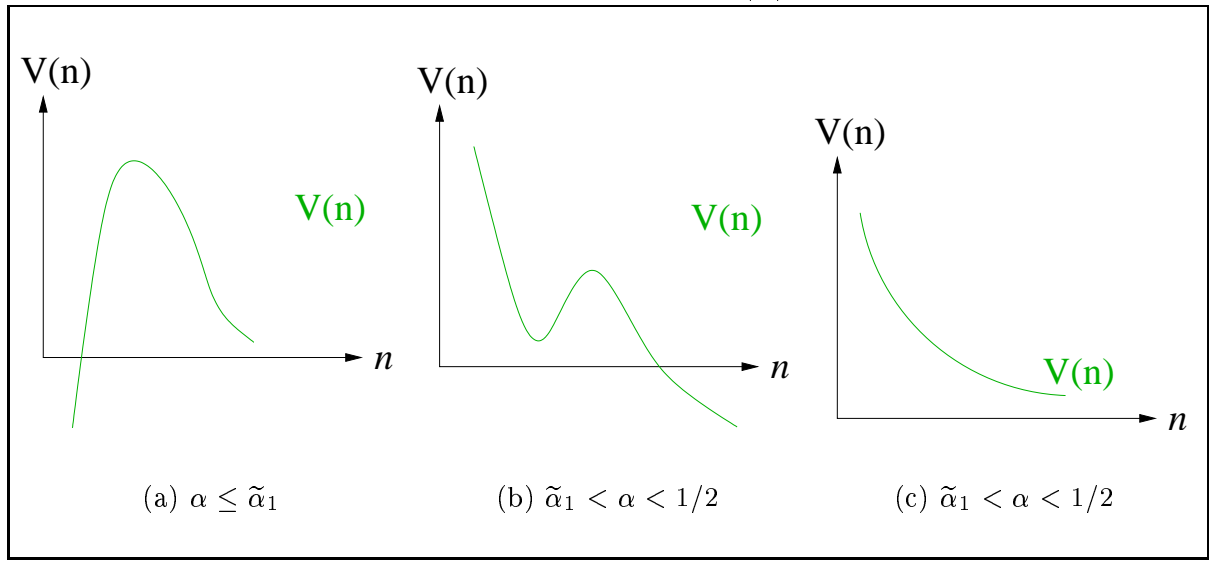

Therefore, with a log-linear utility function and a Cobb-Douglas production function, there exists a unique interior global maximum if and only if the following conditions are satisfied ${ }^{16}$ :

$$
\alpha \leq \frac{\gamma+\beta(1-\gamma)}{1+2 \beta(1-\gamma)} \equiv \widetilde{\alpha}_{1}
$$

and

$$
z>z_{\min }
$$

If $\widetilde{\alpha}_{1}<\alpha<1 / 2$, the global maximum is reached when $n \rightarrow 0$.

The intuition for these conditions can be observed from the planner's first order condition with respect to $n$, equation (5). In order for the planner's objective to be hump-shaped and to achieve an interior maximum, we need that the marginal benefit of children -which corresponds to the left-hand-side of equation (5)- dominates the marginal cost -i.e. the right-hand-side of (5)for low values of $n$, and that the opposite happens for high enough values of $n$. The first condition above ensures that, for sufficiently low values of $n$, the marginal benefit of children is higher than their marginal cost. Observe that it requires that labor is sufficiently important in the production process $(\alpha$ sufficiently low, so that the capital dilution effect is not very important), that the taste for children $\gamma$ is sufficiently high (so that the marginal utility term is important enough), and that future consumption is not discounted too much by individuals ( $\beta$ sufficiently high, so that the intergenerational transfer effect is sufficiently valued). For larger values of $n$, due to the different proportions in which the terms in equation (5) depend on $n$, the marginal cost dominates the marginal benefit and utility is decreasing in $n$. The second condition requires

\footnotetext{
${ }^{16}$ It can also be shown that, in a model with a monetary cost (instead of a time cost) of children and with exogenous labor supply, the result of the existence of an interior optimum for a sufficiently low value of $\alpha$ would still hold.
} 
that the cost per child is high enough so that utility is maximized for a feasible value of the fertility rate, that is for $z n<1$.

\section{B Dynamics and Steady State of the Competi- tive Economy}

This appendix analytically studies the dynamics and the steady state equilibrium of the laissez-faire economy. We focus on the log-linear utility and CobbDouglas production case as specified in equations (60) and (61) in the previous appendix.

Definition 9 Assume an initial capital stock $k_{0}$. A perfect foresight, intertemporal laissez-faire equilibrium is a vector $\left(c_{t}, d_{t}, n_{t}, s_{t}, k_{t}, l_{t}^{f}, w_{t}^{f}, w_{t}^{m}, R_{t}\right)$ starting at $k_{0}$ and satisfying the following conditions:

$$
\begin{gathered}
c_{t}+s_{t}=w_{t}^{m}+w_{t}^{f}\left(1-z n_{t}\right) \\
d_{t+1}=R_{t+1} s_{t} \\
\frac{u^{\prime}\left(c_{t}\right)}{u^{\prime}\left(d_{t+1}\right)}=\beta R_{t+1} \\
\frac{\gamma}{1-\gamma} \frac{u^{\prime}\left(n_{t}\right)}{u^{\prime}\left(c_{t}\right)}=z w_{t}^{f} \\
w_{t}^{f}=f_{l}\left(k_{t}, l_{t}^{f}\right) \\
R_{t}=f_{k}\left(k_{t}, l_{t}^{f}\right) \\
w_{t}^{m}=f\left(k_{t}, l_{t}^{f}\right)-k_{t} f_{k}\left(k_{t}, l_{t}^{f}\right)-l_{t}^{f} f_{l}\left(k_{t}, l_{t}^{f}\right) \\
k_{t+1} n_{t}=s_{t} \\
l_{t}^{f}=1-z n_{t}
\end{gathered}
$$

With the production function in (61), factor prices are given by:

$$
\begin{gathered}
1+r_{t}=R_{t}=A \alpha k_{t}^{\alpha-1}\left(l_{t}^{f}\right)^{1-\alpha} \\
w_{t}^{f}=A(1-\alpha) k_{t}^{\alpha}\left(l_{t}^{f}\right)^{-\alpha} \\
w_{t}^{m}=B
\end{gathered}
$$

With the utility function in (60), the first order condition of the maximization program with respect to consumption (64), together with the budget constraints (62) and (63), allow to define the savings function as follows:

$$
s_{t}=\frac{\beta}{1+\beta}\left[w_{t}^{m}+w_{t}^{f}\left(1-z n_{t}\right)\right]
$$


The first order condition relative to fertility (65) determines the time spent by women raising children:

$$
z n_{t}=\min \left[1, \frac{\gamma}{1+\beta(1-\gamma)}\left(1+\frac{w_{t}^{m}}{w_{t}^{f}}\right)\right]
$$

The log-linear utility function ensures the positivity of $z n_{t}$, and the fertility choice is restricted by the maximum available time of women (1 unit). After substituting (70), (72) and (73) in (75), the amount of time devoted to raising children can be defined by the following implicit function:

$$
H\left(z n_{t}, k_{t}\right) \equiv z n_{t}-\frac{\gamma}{1+\beta(1-\gamma)}\left(1+\frac{B\left(1-z n_{t}\right)^{\alpha}}{A(1-\alpha) k_{t}^{\alpha}}\right)=0
$$

with

$$
\frac{\partial H\left(z n_{t}, k_{t}\right)}{\partial z n_{t}}=1-\frac{\gamma}{1+\beta(1-\gamma)} \frac{B}{A(1-\alpha) k_{t}^{\alpha}} \alpha\left(1-z n_{t}\right)^{\alpha-1}(-1)
$$

This derivative is positive, as any $z n_{t}$ that satisfies the above equation will always be inferior to 1 as long as $k_{t}>0$. Indeed, we can isolate $k_{t}$ from (76) as:

$$
k_{t}=\left(1-z n_{t}\right)\left(\frac{\gamma}{1+\beta(1-\gamma)} \frac{B}{A(1-\alpha)} \frac{1}{z n_{t}-\frac{\gamma}{1+\beta(1-\gamma)}}\right)^{1 / \alpha}
$$

Then, since $\gamma /(1+\beta(1-\gamma))<1, z n_{t}>1$ implies that $k_{t}<0$. Thus for positive values of the capital stock, $z n_{t}<1$. Women will always supply some labor in the market, implying that the time devoted to raising children is strictly smaller than 1.

Since $\frac{\partial H\left(z n_{t}, k_{t}\right)}{\partial z n_{t}}>0$, there exists a function $\Phi\left(k_{t}\right)$ such that:

$$
z n_{t}=\Phi\left(k_{t}\right)
$$

Hence, we can rewrite (76) as:

$$
\Phi\left(k_{t}\right)-\frac{\gamma}{1+\beta(1-\gamma)}\left(1+\frac{B\left[1-\Phi\left(k_{t}\right)\right]^{\alpha}}{A(1-\alpha) k_{t}^{\alpha}}\right)=0
$$

Differentiating this expression, we obtain:

$$
\Phi^{\prime}\left(k_{t}\right)-\frac{\gamma}{1+\beta(1-\gamma)} \frac{B}{A(1-\alpha)}\left[-\frac{\alpha \Phi^{\prime}\left(k_{t}\right)}{\left[1-\Phi\left(k_{t}\right)\right]^{1-\alpha} k_{t}^{\alpha}}-\frac{\alpha\left[1-\Phi\left(k_{t}\right)\right]^{\alpha}}{k_{t}^{\alpha+1}}\right]=0
$$

and therefore:

$$
\Phi^{\prime}\left(k_{t}\right)=-\frac{\left[1-\Phi\left(k_{t}\right)\right]}{k_{t}\left(1+\frac{1+\beta(1-\gamma)}{\gamma} \frac{A}{B} \frac{1-\alpha}{\alpha}\left[1-\Phi\left(k_{t}\right)\right]^{1-\alpha} k_{t}^{\alpha}\right)}<0
$$


The negative sign of the previous expression means that, as capital accumulates, the female wage increases and fertility decreases.

Let's now turn to the accumulation of capital. Using (74) and (75), equation (69) can be written as:

$$
k_{t+1}=\frac{1-\gamma}{\gamma} z \beta w_{t}^{f}
$$

Substituting factor prices,

$$
k_{t+1}=\frac{1-\gamma}{\gamma} z \beta A(1-\alpha)\left(\frac{k_{t}}{1-z n_{t}}\right)^{\alpha}
$$

Hence the evolution of the capital stock is defined by:

$$
k_{t+1}=\frac{1-\gamma}{\gamma} z \beta A(1-\alpha)\left(\frac{k_{t}}{1-\Phi\left(k_{t}\right)}\right)^{\alpha}
$$

Differentiating this expression:

$$
\frac{d k_{t+1}}{d k_{t}}=\frac{1-\gamma}{\gamma} z \beta A(1-\alpha) \alpha\left(\frac{k_{t}}{1-\Phi\left(k_{t}\right)}\right)^{\alpha-1} \frac{1-\Phi\left(k_{t}\right)+k_{t} \Phi^{\prime}\left(k_{t}\right)}{\left[1-\Phi\left(k_{t}\right)\right]^{2}}
$$

Using (77), it is easy to see that:

$$
\frac{1-\Phi\left(k_{t}\right)+k_{t} \Phi^{\prime}\left(k_{t}\right)}{\left[1-\Phi\left(k_{t}\right)\right]^{2}}=\frac{\left[1-\Phi\left(k_{t}\right)\right]^{2-\alpha} \frac{1-\alpha}{\alpha} \frac{A}{B} \frac{1+\beta(1-\gamma)}{\gamma} k_{t}^{\alpha}}{1+\frac{1-\alpha}{\alpha} \frac{A}{B} \frac{1+\beta(1-\gamma)}{\gamma} k_{t}^{\alpha}\left[1-\Phi\left(k_{t}\right)\right]^{1-\alpha}}>0
$$

and therefore, capital accumulation is increasing over time. In addition:

$$
\lim _{k_{t} \rightarrow 0} k_{t+1}=0
$$

Note also that capital stops increasing in the long run:

$$
\lim _{k_{t} \rightarrow \infty} \frac{d k_{t+1}}{d k_{t}}=0
$$

Hence, we can conclude the existence of at least one non-trivial steady state.

We will now prove the existence of a unique non-trivial steady state. The fertility equation (76) at the steady state can be written as:

$$
z n=\frac{\gamma}{1+\beta(1-\gamma)}\left[1+\frac{B(1-z n)^{\alpha}}{A(1-\alpha) k^{\alpha}}\right]
$$

whereas the capital accumulation equation (79) at the steady state becomes:

$$
k=\frac{1-\gamma}{\gamma} A \beta z(1-\alpha)\left(\frac{k}{1-z n}\right)^{\alpha}
$$


Figure 3: Evolution of the capital stock towards the steady state

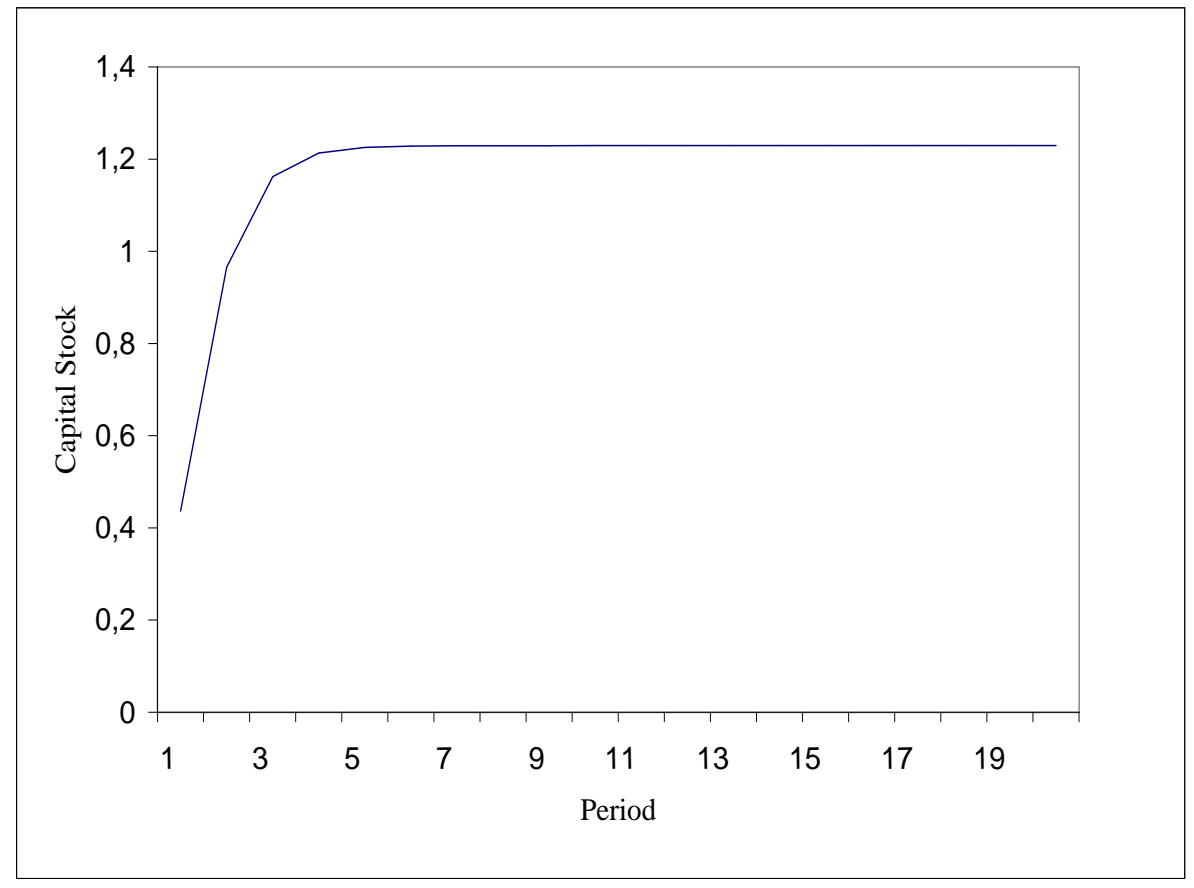

These two equations fully characterize the steady state, determining $n$ and $k$. In fact, we can isolate capital per couple in (81) as follows:

$$
k=\left(\frac{C B}{A(1-\alpha)(z n-C)}\right)^{\frac{1}{\alpha}}(1-z n)
$$

where $C \equiv \frac{\gamma}{1+\beta(1-\gamma)}$. Substituting this into (82), we obtain only one equation in one variable, i.e. the number of children $n$ :

$$
\left(\frac{C B}{A(1-\alpha)(z n-C)}\right)^{\frac{1}{\alpha}}(1-z n)=\frac{1-\gamma}{\gamma} \frac{\beta z C B}{z n-C}
$$

which can be rewritten as:

$$
\left(\frac{C B}{A(1-\alpha)}\right)^{\frac{1}{\alpha}}\left[(z n-C)^{\frac{\alpha-1}{\alpha}}(1-z n)\right]-\frac{1-\gamma}{\gamma} \beta z C B=0
$$

Taking the first derivative with respect to $z n^{17}$ :

$$
\left(\frac{C B}{A(1-\alpha)}\right)^{\frac{1}{\alpha}}[\underbrace{\frac{\alpha-1}{\alpha}(z n-C)^{\frac{\alpha-1}{\alpha}-1}(1-z n)+(z n-C)^{\frac{\alpha-1}{\alpha}}(-1)}_{<0}]
$$

${ }^{17}$ Observe that we know that the term $(z n-C)$ is positive from equation (81). 
which means that this function is decreasing in $z n$. Hence, (83) will have, at the most, one root. Since we have proven the existence of at least one non-trivial steady state, there will be a unique steady state solution.

Figure 4: Evolution of the fertility rate towards the steady state

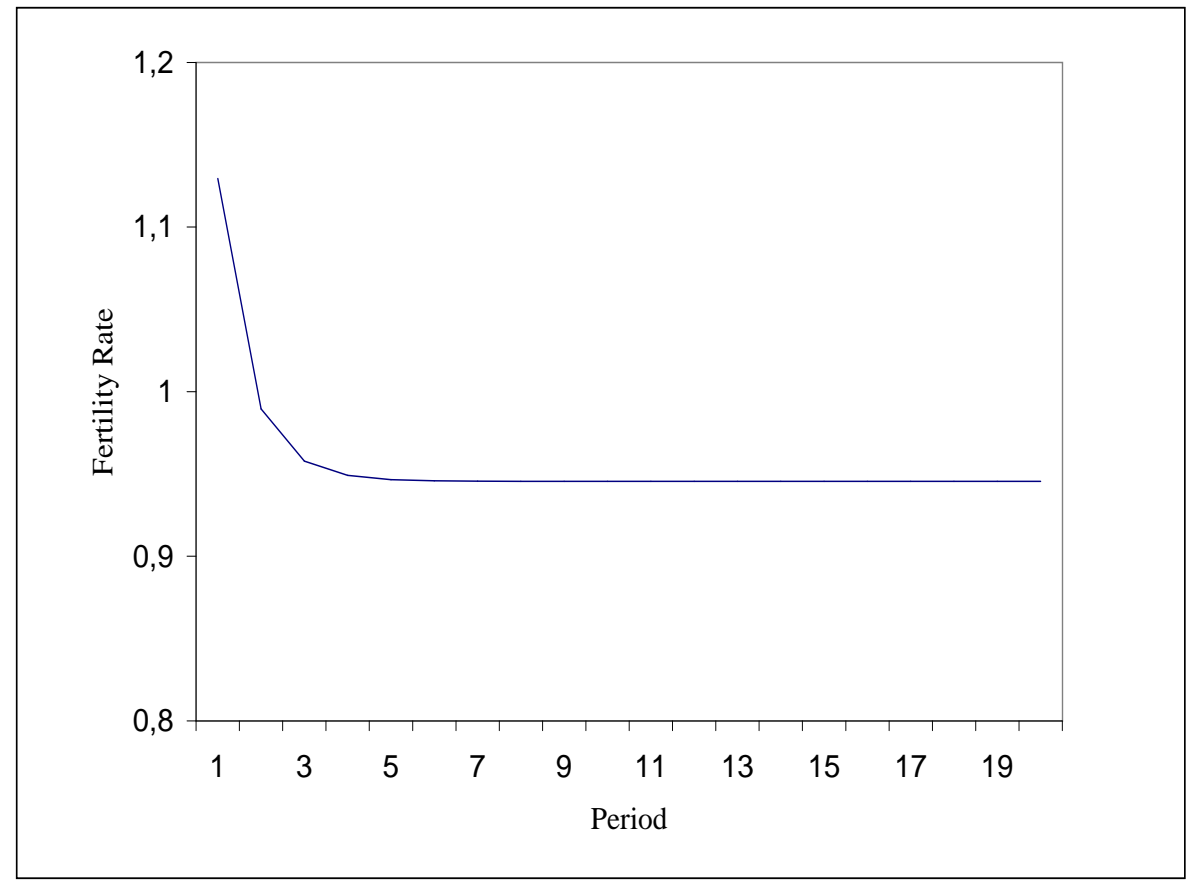

Figures 3 and 4 illustrate the dynamics of the laissez-faire economy for the parameter values indicated in the following table:

\begin{tabular}{|c|c|}
\hline Parameter & Value \\
\hline$\beta$ & 0.5 \\
\hline$\gamma$ & 0.2 \\
\hline$\alpha$ & 0.3 \\
\hline$a$ & 2.4 \\
\hline$b$ & 1 \\
\hline$z$ & 0.4 \\
\hline
\end{tabular}

These figures have been obtained by simulating a temporary shock on the economy that reduces the capital stock (to $14 \%$ of its steady state value) and computing the evolution of capital and fertility on the transitory path towards the steady state. 


\section{CESifo Working Paper Series}

(for full list see www.cesifo.de)

987 Dan Ariely, Axel Ockenfels and Alvin E. Roth, An Experimental Analysis of Ending Rules in Internet Auctions, July 2003

988 Paola Conconi and Carlo Perroni, Self-Enforcing International Agreements and Domestic Policy Credibility, July 2003

989 Charles B. Blankart and Christian Kirchner, The Deadlock of the EU Budget: An Economic Analysis of Ways In and Ways Out, July 2003

990 M. Hasham Pesaran and Allan Timmermann, Small Sample Properties of Forecasts from Autoregressive Models under Structural Breaks, July 2003

991 Hyun Park, Apostolis Philippopoulos and Vangelis Vassilatos, On the Optimal Size of Public Sector under Rent-Seeking competition from State Coffers, July 2003

992 Axel Ockenfels and Alvin E. Roth, Late and Multiple Bidding in Second Price Internet Auctions: Theory and Evidence Concerning Different Rules for Ending an Auction, July 2003

993 Pierre Salmon, The Assignment of Powers in an Open-ended European Union, July 2003

994 Louis N. Christofides and Chen Peng, Contract Duration and Indexation in a Period of Real and Nominal Uncertainty, July 2003

995 M. Hashem Pesaran, Til Schuermann, Björn-Jakob Treutler, and Scott M. Weiner, Macroeconomic Dynamics and Credit Risk: A Global Perspective, July 2003

996 Massimo Bordignon and Sandro Brusco, On Enhanced Cooperation, July 2003

997 David F. Bradford, Addressing the Transfer-Pricing Problem in an Origin-Basis X Tax, July 2003

998 Daniel Gros, Who Needs Foreign Banks?, July 2003

999 Wolfram Merzyn and Heinrich W. Ursprung, Voter Support for Privatizing Education: Evidence on Self-Interest and Ideology, July 2003

1000 Jo Thori Lind, Fractionalization and the Size of Government, July 2003

1001 Daniel Friedman and Donald Wittman, Litigation with Symmetric Bargaining and TwoSided Incomplete Information, July 2003 
1002 Matthew Clarke and Sardar M. N. Islam, Health Adjusted GDP (HAGDP) Measures of the Relationship Between Economic Growth, Health Outcomes and Social Welfare, July 2003

1003 Volker Grossmann, Contest for Attention in a Quality-Ladder Model of Endogenous Growth, August 2003

1004 Marcel Gérard and Joan Martens Weiner, Cross-Border Loss Offset and Formulary Apportionment: How do they affect multijurisdictional firm investment spending and interjurisdictional tax competition?, August 2003

1005 Burkhard Heer, Nonsuperneutrality of Money in the Sidrauski Model with Heterogeous Agents, August 2003

1006 V. Anton Muscatelli, Piergiovanna Natale, and Patrizio Tirelli, A Simple and Flexible Alternative to the Stability and Growth Pact Deficit Ceilings. Is it at hand?, August 2003

1007 Reto Foellmi and Josef Zweimüller, Inequality and Economic Growth: European Versus U.S. Experiences, August 2003

1008 James S. Costain and Michael Reiter, Business Cycles, Unemployment Insurance, and the Calibration of Matching Models, August 2003

1009 Marco Runkel, Optimal Contest Design when the Designer's Payoff Depends on Competitive Balance, August 2003

1010 Donald O. Parsons, Torben Tranaes and Helene Bie Lilleør, Voluntary Public Unemployment Insurance, August 2003

1011 Rüdiger Pethig and Andreas Wagener, Profit Tax Competition and Formula Apportionment, August 2003

1012 Johan Willner, Privatisation and Public Ownership in Finland, August 2003

1013 Seppo Kari and Jouko Ylä-Liedenpohja, Taxation and Valuation of International Real Investments, August 2003

1014 James Heckman, Rosa Matzkin and Lars Nesheim, Simulation and Estimation of Hedonic Models, August 2003

1015 Biswa N. Bhattacharyay, Towards a Macro-Prudential Leading Indicators Framework for Monitoring Financial Vulnerability, August 2003

1016 J. Stephen Ferris and Stanley L. Winer, Searching for Keynes: With Application to Canada, 1870-2000, August 2003

1017 Massimo Bordignon, Luca Colombo and Umberto Galmarini, Fiscal Federalism and Endogenous Lobbies’ Formation, August 2003 
1018 Annette Alstadsæter, The Dual Income Tax and Firms' Income Shifting through the Choice of Organizational Form and Real Capital Investments, August 2003

1019 Peter Fredriksson and Bertil Holmlund, Optimal Unemployment Insurance Design: Time Limits, Monitoring, or Workfare?, August 2003

1020 Kashif S. Mansori, Following in their Footsteps: Comparing Interest Parity Conditions in Central European Economies to the Euro Countries, August 2003

1021 Christoph Borgmann and Matthias Heidler, Demographics and Volatile Social Security Wealth: Political Risks of Benefit Rule Changes in Germany, August 2003

1022 Kjell Erik Lommerud, Bjørn Sandvik and Odd Rune Staume, Good Jobs, Bad Jobs and Redistribution, August 2003

1023 Patrick Karl O’Brien, The Governance of Globalization: The Political Economy of Anglo-American Hegemony, 1793-2003, September 2003

1024 Antonio Ciccone and Giovanni Peri, Skills’ Substitutability and Technological Progress: U.S. States 1950-1990, September 2003

1025 Bjørn Sandvik, Optimal Taxation and Normalisations, September 2003

1026 Massimo Bordignon and Gilberto Turati, Bailing Out Expectations and Health Expenditure in Italy, September 2003

1027 José A. Herce, Namkee Ahn, Ricard Génova, and Joaquín Pereira, Bio-Demographic and Health Aspects of Ageing in the EU, September 2003

1028 John Komlos and Marieluise Baur, From the Tallest to (One of) the Fattest: The Enigmatic Fate of the American Population in the $20^{\text {th }}$ Century, September 2003

1029 Stefan Napel and Mika Widgrén, Bargaining and Distribution of Power in the EU's Conciliation Committee, September 2003

1030 Kai Li and Dale J. Poirier, Relationship Between Maternal Behavior During Pregnancy, Birth Outcome, and Early Childhood Development: An Exploratory Study, September 2003

1031 Ivar Ekeland, James J. Heckman, and Lars Nesheim, Identifcation and Estimation of Hedonic Models, September 2003

1032 Kjetil Bjorvatn and Alexander W. Cappelen, Decentralization and the Fate of Minorities, September 2003

1033 Lars-Erik Borge and Jørn Rattsø, The Relationships Between Costs and User Charges: The Case of a Norwegian Utility Service, September 2003

1034 Maureen Were and Nancy N. Nafula, An Assessment of the Impact of HIV/AIDS on Economic Growth: The Case of Kenya, September 2003 
1035 A. Lans Bovenberg, Tax Policy and Labor Market Performance, September 2003

1036 Peter Birch Sørensen, Neutral Taxation of Shareholder Income: A Norwegian Tax Reform Proposal, September 2003

1037 Roberta Dessi and Sheilagh Ogilvie, Social Capital and Collusion: The Case of Merchant Guilds, September 2003

1038 Alessandra Casarico and Carlo Devillanova, Capital-skill Complementarity and the Redistributive Effects of Social Security Reform, September 2003

1039 Assaf Razin and Efraim Sadka, Privatizing Social Security Under Balanced-Budget Constraints: A Political-Economy Approach, September 2003

1040 Michele Moretto, Paolo M. Panteghini, and Carlo Scarpa, Investment Size and Firm's Value under Profit Sharing Regulation, September 2003

1041 A. Lans Bovenberg and Peter Birch Sørensen, Improving the Equity-Efficiency Tradeoff: Mandatory Savings Accounts for Social Insurance, September 2003

1042 Bas van Aarle, Harry Garretsen, and Florence Huart, Transatlantic Monetary and Fiscal Policy Interaction, September 2003

1043 Jerome L. Stein, Stochastic Optimal Control Modeling of Debt Crises, September 2003

1044 Thomas Stratmann, Tainted Money? Contribution Limits and the Effectiveness of Campaign Spending, September 2003

1045 Marianna Grimaldi and Paul De Grauwe, Bubbling and Crashing Exchange Rates, September 2003

1046 Assar Lindbeck and Dennis J. Snower, The Firm as a Pool of Factor Complementarities, September 2003

1047 Volker Grossmann, Firm Size and Diversification: Asymmetric Multiproduct Firms under Cournot Competition, September 2003

1048 Dan Anderberg, Insiders, Outsiders, and the Underground Economy, October 2003

1049 Jose Apesteguia, Steffen Huck and Jörg Oechssler, Imitation - Theory and Experimental Evidence, October 2003

1050 G. Abío, G. Mahieu and C. Patxot, On the Optimality of PAYG Pension Systems in an Endogenous Fertility Setting, October 2003 